\title{
Binding of proline- and hydroxyproline-containing peptides and proteins to the capillary wall
}

\author{
I. Hamrníkováa ${ }^{\text {I. I. Mikšík }}{ }^{\mathrm{b}, *}$, Z. Deyl, ${ }^{\mathrm{b}, \mathrm{c}}$, V. Kašicka ${ }^{\mathrm{d}}$ \\ ${ }^{a}$ 2nd Medical School, Charles University, Prague, Czech Republic \\ ${ }^{\mathrm{b}}$ Institute of Physiology, Academy of Sciences of the Czech Republic, Videnska 1083, CZ-14220 Prague 4, Czech Republic \\ ${ }^{\mathrm{c} D e p a r t m e n t}$ of Analytical Chemistry, Institute of Chemical Technology, Prague, Czech Republic \\ ${ }^{\mathrm{d}}$ Institute of Organic Chemistry and Biochemistry, Academy of Sciences of the Czech Republic, Prague, Czech Republic
}

\begin{abstract}
Sticking of peptides (as demonstrated by peak distortion) containing a high proportion of glycine and proline residues to the capillary wall was investigated. At acid $\mathrm{pH}$ where the carboxy terminal proline (e.g. Gly-Pro) is protonated, distinct sticking of these peptides occurred. On the contrary, the Pro-Gly peptide yielded a well shaped peak. At alkaline $\mathrm{pH}$, where the situation was reversed, the peptide sticking most to the wall was Gly-Gly, while the behaviour of the dipeptides possessing $\mathrm{N}$ - or $\mathrm{C}$-terminal proline did not suffer from sticking to the wall.

It was concluded that the separation of simple proline- and glycine-containing dipeptides can be partly optimized by manipulating the $\mathrm{pH}$ of the background electrolyte; particularly if cetyltrimethylammonium bromide, methanol or acetonitrile is added to the run buffer (reversed polarity mode with cetyltrimethylammonium bromide). However, all attempts to resolve more complex mixtures of proline- (and hydroxyproline-) containing di- and tripeptides failed; addition of an organic modifier, i.e. methanol and acetonitrile, hexylamine, triethylamine and cetyltrimethylammonium bromide was unsuccessful. Such separations can be materialized by using simple $25 \mathrm{mmol} / 1$ phosphate buffer at $\mathrm{pH} 10.5$ provided that the sample is dissolved in (aqueous) $17.5 \mathrm{mmol} / 1 \mathrm{Brij}$ or $33 \mathrm{mmol} / 1$ sodium dodecyl sulfate. These systems are also applicable to large polypeptides rich in proline, hydroxyproline and glycine: typically parent collagen $\alpha$-chains, their dimers, trimers and higher polymers were successfully separated. (C) 1999 Elsevier Science B.V. All rights reserved.
\end{abstract}

Keywords: Wall adsorption; Proteins; Peptides

\section{Introduction}

The phenomenon of protein/peptide sticking to the capillary wall is well known and numerous attempts of how to avoid it can be traced in the literature. It is widely accepted that the main reason for this phenomenon results from the charged silanol

*Corresponding author. Tel.: +420-2-4752534; fax: +420-24752558.

E-mail address: miksik@biomed.cas.cz (I. Mikšík) groups and their interaction with countercharged functionalities in the polypeptide chain, mainly free $\epsilon$-aminogroups of lysine, free $\mathrm{N}$-terminal amino group and the guanidine moiety in the side chain of arginine (for review see [1]). Logical ways for circumventing these effects are either to oppress the dissociation of the silanol groups by running the separation at a very low $\mathrm{pH}(\sim 2.5$, see $[2,3])$ or, on the contrary, to depress the dissociation of the polypeptide chain nitrogen functionalities (amino and guanidino groups, see Ref. [4]) by running the 
separation above their isoelectric point. There are other possibilities (coating and dynamic coating of the capillary) as well; see Refs. [5-13].

Additional possibilities for minimizing protein/ peptide absorption are the use of metal salts in the background electrolyte [14] or the application of zwitterionic buffers [15].

On the other hand we have demonstrated in our previous reports $[16,17]$ that polypeptide chains of large internal homogeneity possessing a proportionally higher amount of hydrophobic domains in their fragments (typically $\mathrm{CNBr}$ derived collagen polypeptides ${ }^{1}$ ) are separated during capillary electrophoresis according to their molecular mass. In other words longer peptides containing more hydrophobic areas are eluted later and the relation between relative migration and the number of these domains is linear, while no correlation exists with the amino and/or guanidino functionalities present in the individual fragments. As the electrophoretic profile of such a set of peptides is practically identical with the profile obtained by reversed-phase chromatography, it was proposed that in acid buffers $(\mathrm{pH}$ 2.5) collagen fragments interact via hydrophobic interactions with the inner surface of the capillary wall and are step-by-step eluted to the detector by endoosmotically driven background electrolyte. It should be emphasized that the typical collagenous sequence is Gly-Pro-X where $\mathrm{X}$ can be either a hydroxyproline residue or any other amino acid with a small side chain, most frequently glycine and alanine (glycine constitutes one third of all amino acids in the collagen molecule) [18].

It appeared, therefore, interesting to follow the behaviour of small proline-possessing peptides during capillary electrophoresis. In the current communication we dealt also with a set of proline- or hydroxyproline-containing peptides with the aim to work out a method that would respect the specific features of these peptides and could be (after proper modification) applicable also for large collagen polypeptides.

${ }^{1}$ For collagen/collagen fragments structure and nomenclature see [18].

\section{Experimental}

\subsection{Apparatus and operating conditions}

Beckman P/ACE 5500 capillary electrophoresis (Fullerton, CA, USA) with P/ACE Station was used throughout this study; separations were run at $15 \mathrm{kV}$ in bare fused silica capillary $(47 \mathrm{~cm} \times 75 \mu \mathrm{m}$ I.D., 40 $\mathrm{cm}$ to the detector) with grounded cathode with sample injection at the anodic side. UV absorbance at $200 \mathrm{~nm}$ was used for detection. Generally $25 \mathrm{mmol} / 1$ phosphate buffers of the desired $\mathrm{pH}$ were used; electrophoretic runs were carried out at $25^{\circ} \mathrm{C}$ with samples containing $100 \mu \mathrm{g} / \mathrm{ml}$ of the separated peptides each or $200 \mu \mathrm{g} / \mathrm{ml}$ of collagen. Sample injection was done hydrodynamically by overpressure $(3.45 \mathrm{kPa}, 1 \mathrm{~s})$. Before analysis the capillary was conditioned by running buffer $(5 \mathrm{~min})$. After every run the capillary was flushed with the running buffer (5 min), water (2 min), $1 M \mathrm{NaOH}$ (5 min), water $(2 \mathrm{~min})$ and in the case of separation with acidic buffers followed another wash with $3 \mathrm{M} \mathrm{HCl}$ (5 min) and water (2 min).

\subsection{Chemicals}

All peptides and Brij 35 were obtained from Sigma (St. Louis, MO, USA), SDS (sodium dodecyl sulfate) was from Merck (Darmstadt, Germany), all other chemicals (buffer components, organic modifiers and surfactants) were obtained from Lachema (Brno, Czech Republic) and were of the highest available purity. Buffer and wash solutions were prepared in Milli-Q Water (Millipore, Bedford, MA, USA). For separations in the presence of detergents the peptide samples were dissolved in $17.5 \mathrm{mmol} / 1$ Brij or $33 \mathrm{mmol} / \mathrm{l} \mathrm{SDS}$; samples of collagen were applied in $50 \mathrm{mmol} / 1$ Brij 35 (aqueous solution, unbuffered).

\section{Results}

At acid $\mathrm{pH}$ where the carboxyl end of the peptide Gly-Pro is protonated and the amino terminal is fully charged, sticking of the Gly-Pro peptide occurred while peptides with the sequence Pro-Gly resulted in an fair peak as compared to diglycine as 

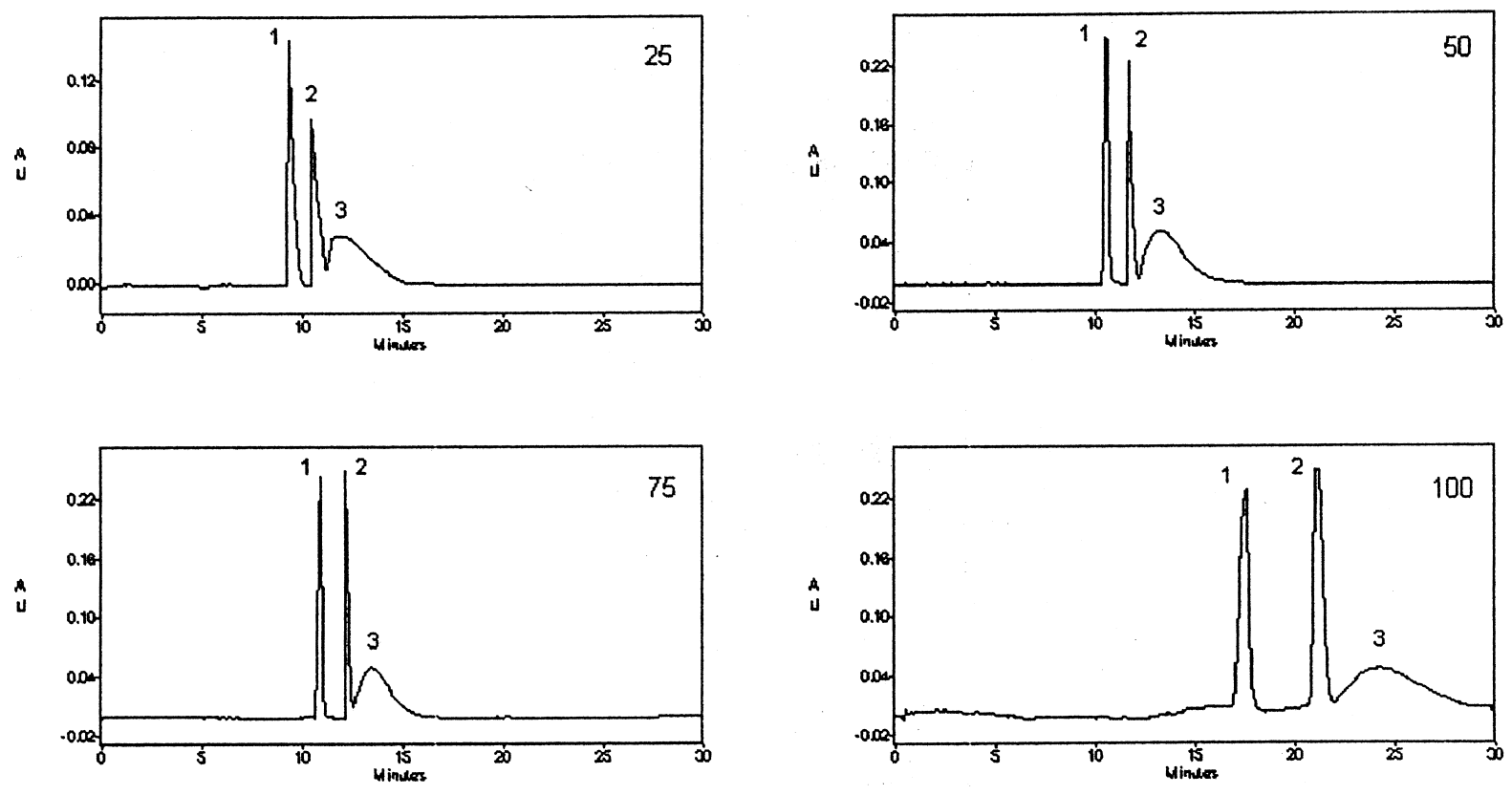

Fig. 1. Separation of a three component mixture (Gly-Gly [1], Pro-Gly [2] and Gly-Pro [3]) at pH 2.5 and different molarity of the background electrolyte (sodium phosphate, $25-100 \mathrm{mmol} / \mathrm{l}$ ).

internal standard. The sticking was demonstrated by shallow broad peak formation (for Gly-Pro see Fig. 1). Increased concentration of the buffer resulted, as expected, in a decrease of the endoosmotic flow and consequently, increased migration times, however, the number of the theoretical plates were low and sticking of the Gly-Pro peptide persisted. Assuming that sticking of the Gly-Pro peptide is at least partly due to hydrophobic interactions with the capillary wall we investigated the effect of the organic modifier addition to the background electrolyte (Fig. 2). Addition of either $10 \%$ or $20 \%$ of methanol or $10 \%$ acetonitrile to the buffer was without a marked change of the profile. A general distortion of the profile (though partial separation was observable) can be shown with $30 \%$ methanol in the run buffer. Increased concentration of acetonitrile helped to partly abolish the broad peak of the Gly-Pro peptide, however, at the expense of distorting the separation. At alkaline $\mathrm{pH}$ where the situation was reversed, i.e. where the amino terminal was uncharged while the peptide was possessing a charged carboxyl, the situation was altered (Fig. 3); the peptide sticking to the wall was Gly-Gly while the behaviour of the dipeptides possessing proline at its C-terminus was acceptable. In particular good separation was obtained in $25 \mathrm{mmol} / 1$ phosphate buffer at $\mathrm{pH}$ 8.0. When observing the separation at decreasing $\mathrm{pH}$ values (data not shown), only a single (heavily distorted peak with the indication of a forepeak) was seen at $\mathrm{pH}$ 4.8. Going further down with the $\mathrm{pH}$ value the changed elution order of the three peptides was observed, namely diglycine emerging first and Gly-Pro last. However, as mentioned already, at the same time heavy sticking of the Gly-Pro peptide was observed.

When at the optimized $\mathrm{pH}=8$ either methanol or ethanol (10 or $20 \%$ ) was added to the background electrolyte, a better resolution of the Gly-Pro peak from the couple of proline possessing peptides was observed (Fig. 3). At higher $\mathrm{pH}$ values, however, considerable distortion of all three peaks occurred.

Addition of hexylamine $(2-5 \mathrm{mmol} / \mathrm{l}$ in the background electrolyte) as the capillary wall shielding compound at alkaline $\mathrm{pH}$ did not bring acceptable results (Fig. 4). The tendency of changes was 

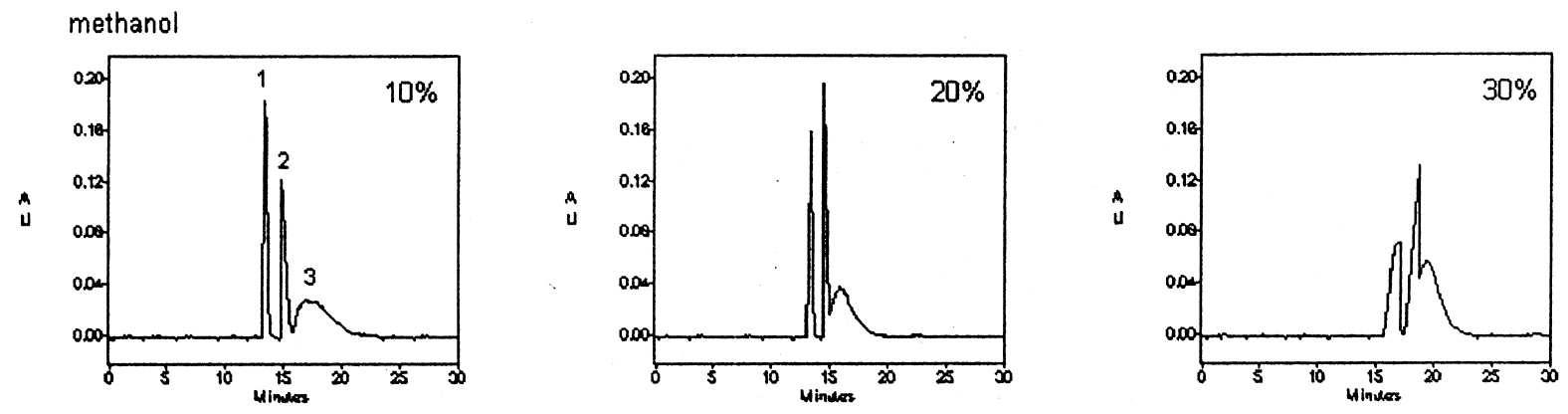

acetonitrile
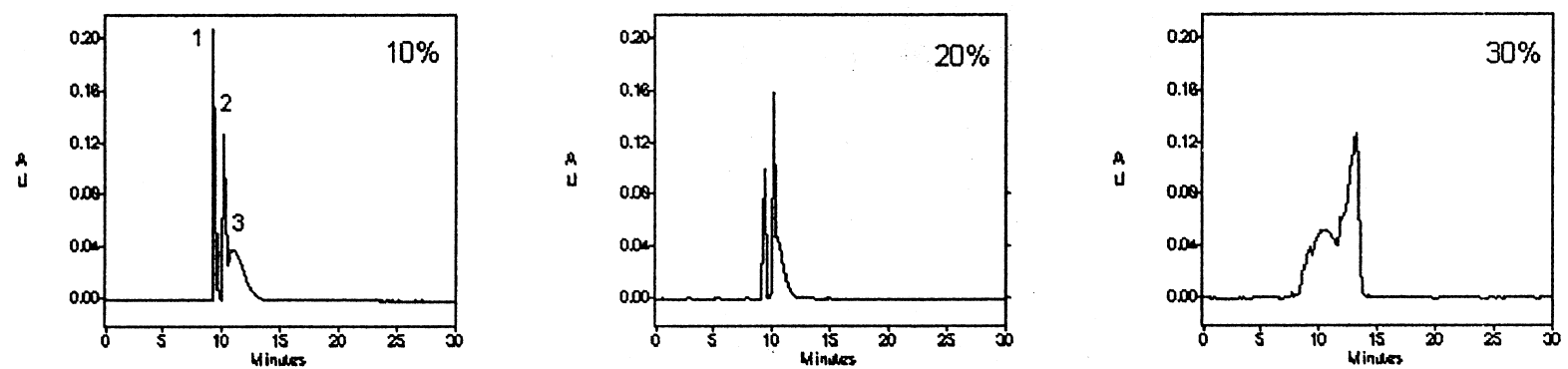

Fig. 2. Effect of the increasing proportion of the organic modifier (methanol or acetonitrile) in the acid background electrolyte (25 mmol/1 phosphate $\mathrm{pH}$ 2.5) on the separation of dipeptides. Peak identification as in Fig. 1.

$10 \%$ methanol

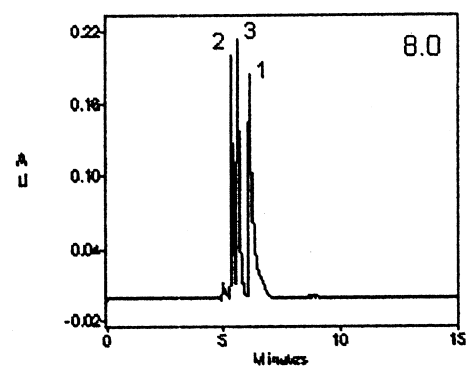

$20 \%$ methanol

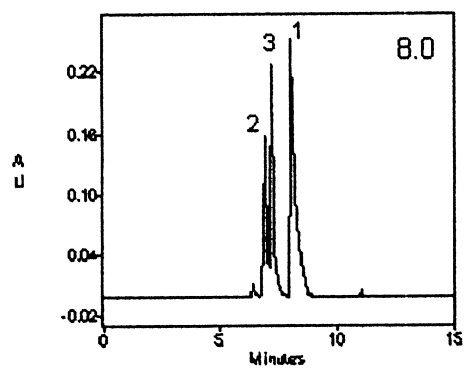

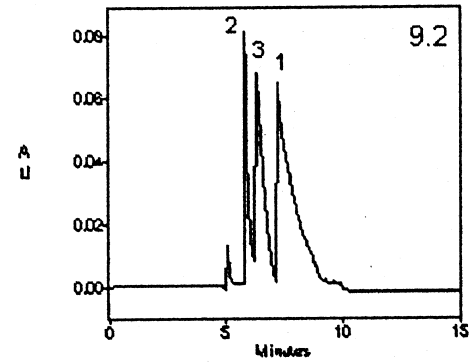

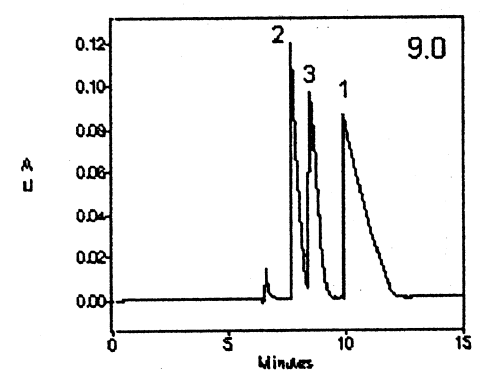

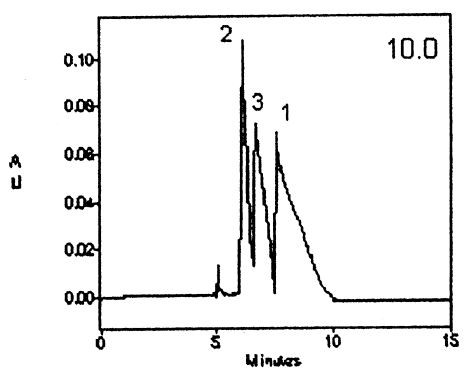

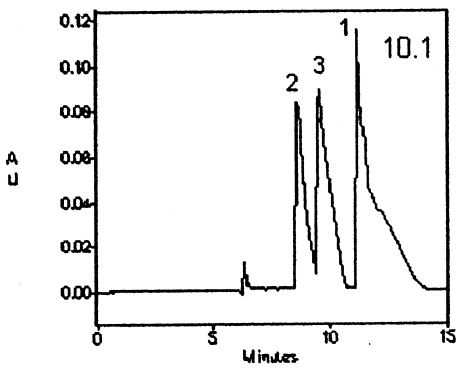

Fig. 3. Effect of the concentration of the organic modifier in the background electrolyte (10\% or $20 \%$ methanol) with increasing pH on the separation of dipeptides. Notice the altered order of eluting peptides compared to Fig. 1. Peak identification as in Fig. 1. 
A

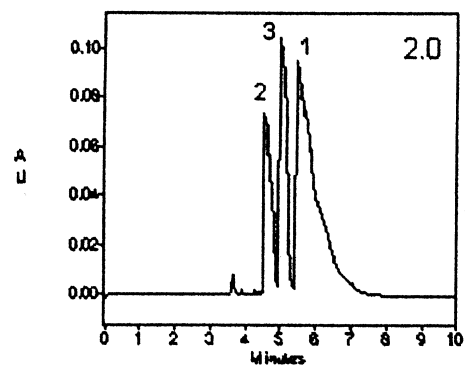

B

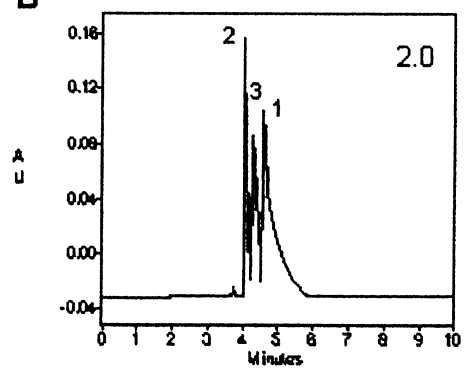

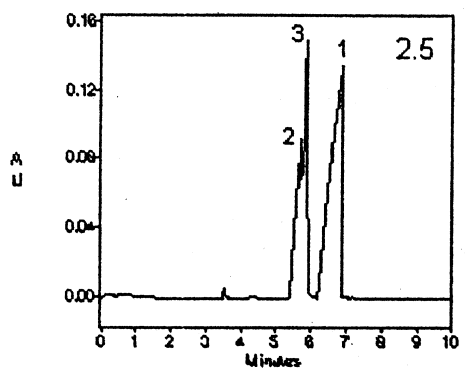
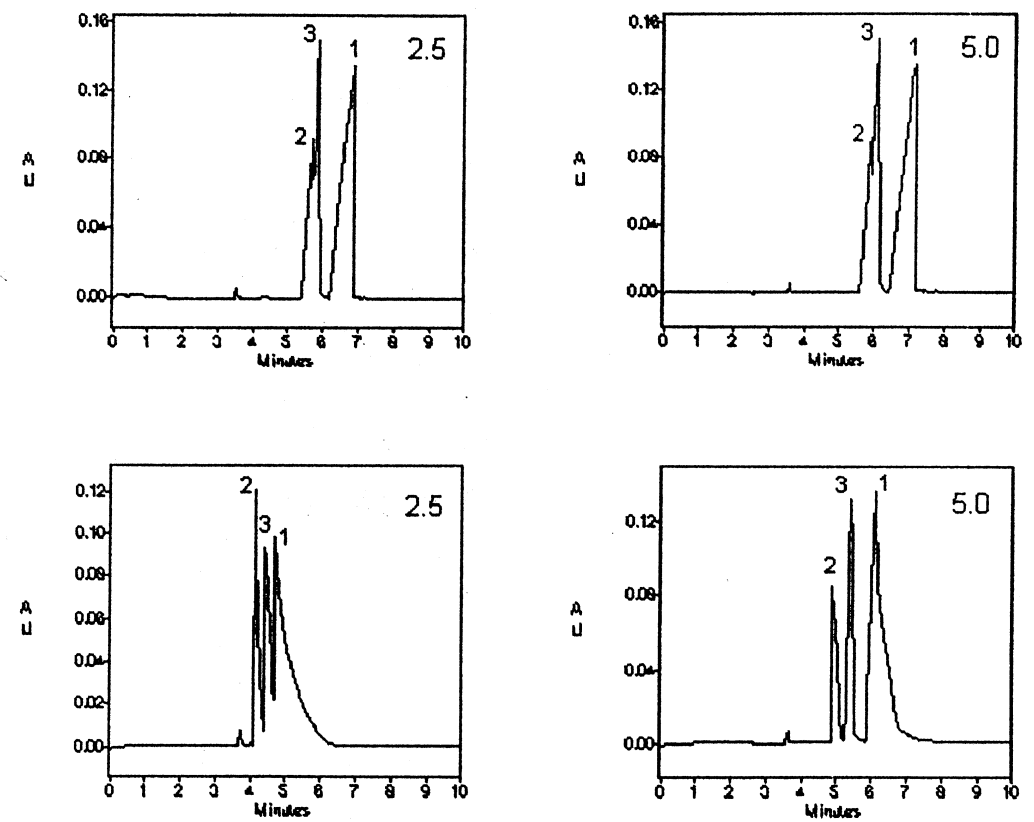

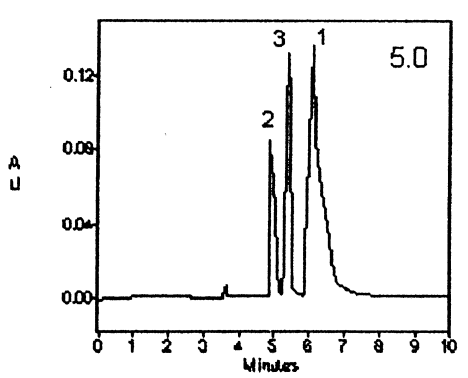

Fig. 4. Effect of the addition of hexylamine (A) and triethylamine (B) to $25 \mathrm{mmol} / 1$ sodium phosphate buffer at $\mathrm{pH} 9.24$ on the separation of dipeptides. Peak identification as in Fig. 1, mmol/1 of the particular amine as indicated.

observed if triethylamine instead of hexylamine was used as dynamic modifier of the capillary wall followed the same pathway. However, the addition of cetyltrimethylammonium bromide decreased sticking of the Gly-Gly dipeptide to the capillary wall, though some fronting (owing to the reversed polarity mode) was observed (Fig. 5).

At $\mathrm{pH} 8$ very little sticking was observed in the absence of any modifier (data not shown) and reasonable separations were obtained also at higher $\mathrm{pH}$ values (up to 10.5) as well with the three membered series of peptides described so far. If another mixture was used (Pro-Ala, Val-Pro and Pro-Gly-Gly) (Fig. 6) only the peak of Val-Pro was revealed followed by two broad plateaus containing all the other members of the test mixture (proven by re-running the accumulated sample, data not shown). The profile seen in Fig. 6 was identical in three consecutive runs. However, the background electrolyte had to be made at least $10.0 \mathrm{mmol} / 1$ with respect to Brij 35 as otherwise heavy clogging of the capillary was observed. If the surfactant used was
SDS at a $10 \mathrm{mmol} / 1$ concentration in the background electrolyte, Val-Pro emerged as a well distinquishable peak, while all the other members of the series formed a broad plateau (Fig. 7).

In order to avoid sticking, we have used addition of two surfactants at higher concentration, namely $17.5 \mathrm{mmol} / 1 \mathrm{Brij}$ or $33 \mathrm{mmol} / 1 \mathrm{SDS}$ to the background electrolyte. No separation was observed and all components eluted as a single peak at around 4 min ( $25 \mathrm{mmol} / 1$ phosphate buffer $\mathrm{pH} 8.5)$. Also no improved separation was seen under these conditions at $\mathrm{pH} 10.5$.

Nearly complete separation of the more complex text mixture consisting of Gly-Pro, Val-Pro, ProHyp, Leu-Pro, Gly-Hyp, Pro-Ala, Pro-Gly, ProIle and Pro-Gly-Gly was observed at pH 10.5 in 25 mmol/1 phosphate buffer (Fig. 8A). However, in this case only the sample was made $17.5 \mathrm{mmol}$ with respect to Brij 35, while the background electrolyte was devoid of the detergent. Increasing the $\mathrm{pH}$ to 11.5 (Fig. 8B) as well as $\mathrm{pH}$ decrease to 8.5 (data not shown) did not reveal any improvement of the 

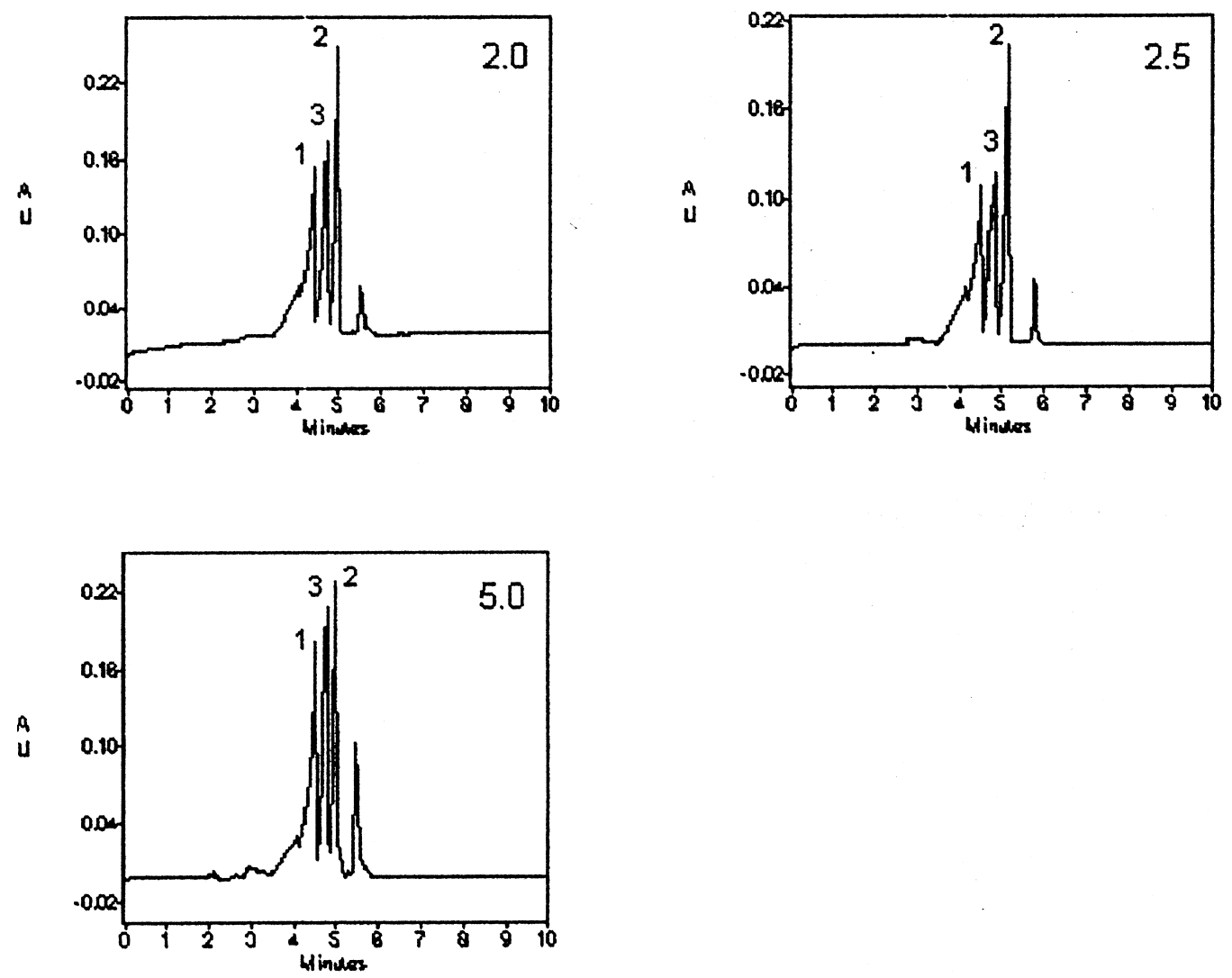

Fig. 5. Separation of the three dipeptides at $\mathrm{pH} 9.25$ in $25 \mathrm{mmol} / 1$ sodium phosphate buffer with increasing proportion of cetyltrimethyl ammonium bromide in the background electrolyte $(\mathrm{mmol} / \mathrm{l})$ as indicated. (Reversed polarity mode, high voltage at cathode). Peak identification as in Fig. 1.

separation. There were three critical pairs in the set which comigrated at $\mathrm{pH} 8.5$, namely Val-Pro+ProHyp, Leu-Pro+Gly-Hyp and Pro-Gly+Pro-Ile; at $\mathrm{pH} 11.5$ Val-Pro was partly resolved from a fused peak of Pro-Hyp, Leu-Pro and Gly-Hyp. The peak emerging at about $3 \mathrm{~min}$ is a system peak.

Dissolving the sample in $33 \mathrm{mmol} / 1$ SDS rather than in $17.5 \mathrm{mmol} / 1$ Brij 35 (Fig. 8C) yielded a comparable profile, however the separation (selectivity of the system) was much worse and the consistently appearing bump at the end of the electropherogram indicated that some peptides of the set may not have been eluted in the individual peaks (1-10). However, this system was capable of resolving Val-Pro and Pro-Hyp which comigrated if the sample was dissolved in $17.5 \mathrm{mmol} / \mathrm{l} \mathrm{Brij}$, while peaks 8-10 comigrated at the end of the electropherogram.

A similar system, i.e. containing no detergent in the background electrolyte but using protein sample dissolved in the presence of a detergent $(33 \mathrm{mmol} / \mathrm{l}$ Brij 35) can be used also for the separation of collagen parent $\alpha$-chains. As shown in Fig. 9, a complete separation of $\alpha_{1}$ and $\alpha_{2}$ chains, $\beta$ and $\gamma$-polymers can be obtained; the large plateau emerging after the $\gamma$-chains represents higher aggregates. This peak nearly vanishes if the sample is boiled before application (Brij is added after the boiling period). Negative peaks are tentatively ascribed to a local disbalance resulting from binding background electrolyte components to the collagen sample/fraction. 


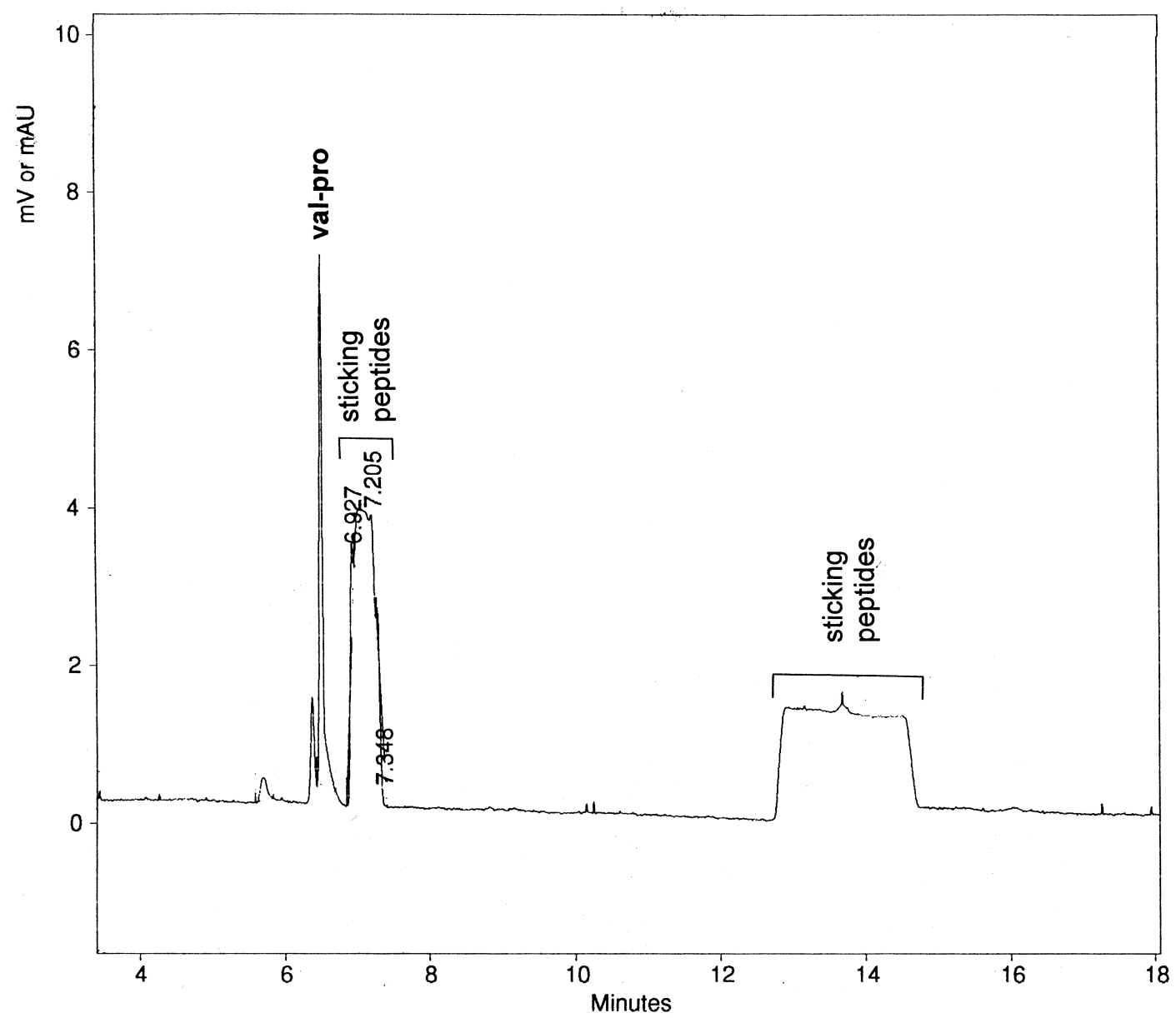

Fig. 6. Separation of a mixture of three peptides (Pro-Ala, Val-Pro and Pro-Gly-Gly) at pH 10.5 in 25 mmol/1 sodium phosphate buffer $(10 \mathrm{mmol} / 1$ with respect to Brij). Note the large flat zones of increased absorbancy representing step-wise elution of peptides strongly bound to the capillary wall.

\section{Discussion}

There are several possibilities how to achieve better separations of glycine and proline rich peptides, namely (i) by adjusting carefully the $\mathrm{pH}$ of the background electrolyte, (ii) to decrease the polarity of the run buffer by the addition of organic solvents (acetonitrile, methanol), (iii) by exploiting the hydrophobic domains of the separated entities using a surfactant (pseudophase) containing run buffer. An additional possibility is to use a surfactant plug that would prevent adsorption of the peptides/proteins to the capillary wall and establish a partition equilib- rium between the capillary wall and the passing by micelles in the pseudophase. The latter speculation was based on the fact that either hydrophobic coating of the capillary or using SDS micelles in the run buffer prevented binding of the peptides/proteins to the capillary wall [19]. This was further supported by the observation of Lloyd and Wätzig [20] that introducing an SDS wash can effectively remove all peptides/proteins sticking to the capillary wall.

With the short glycine and proline containing dipeptides the electrophoretic behaviour is rather simple. Switching from acid to alkaline $\mathrm{pH}$ the order of migrating peptides is reversed following their $\mathrm{pK}_{\mathrm{a}}$ 


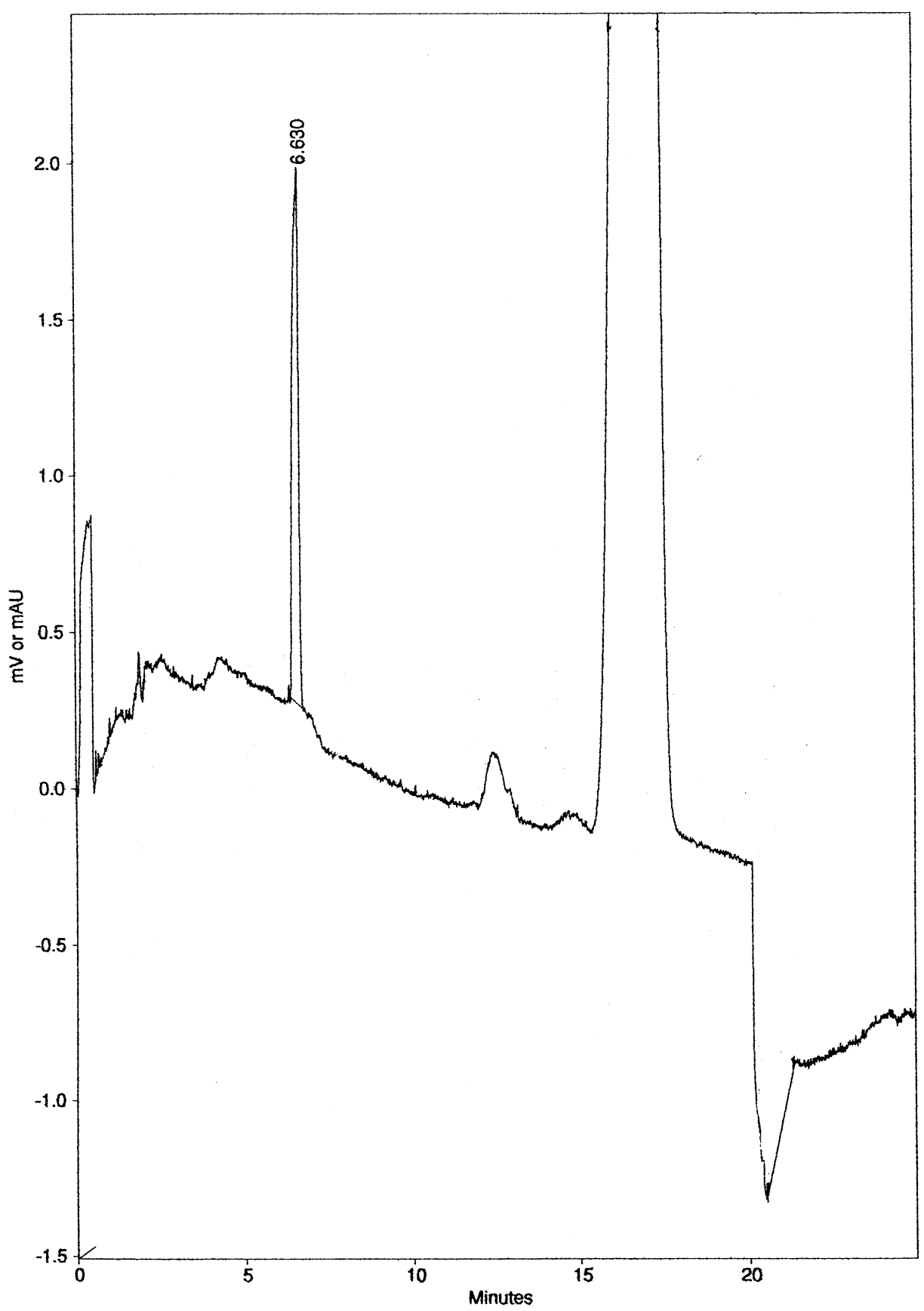

Fig. 7. Separation of Gly-Pro, Val-Pro, Pro-Hyp, Leu-Pro, Gly-Hyp, Gly-Pro-Ala, Pro-Ala, Pro-Gly, Pro-Ile and Pro-Gly-Gly at pH 10.5 in $25 \mathrm{mmol} / 1$ phosphate made $10 \mathrm{mmol} / 1$ with respect to SDS. Except Gly-Pro all the other peptides emerge in a large single peak. 

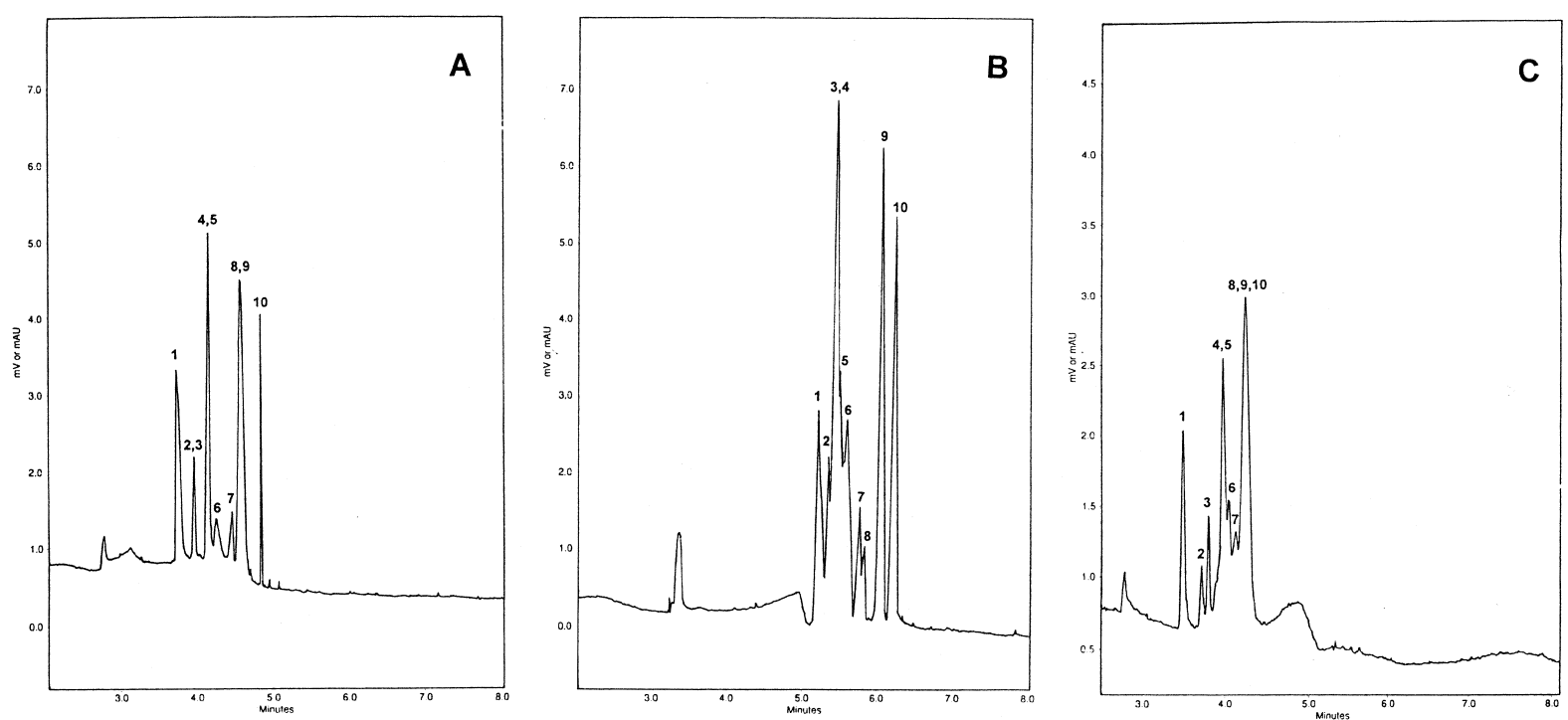

Fig. 8. (A) Separation of Gly-Pro (1), Val-Pro (2), Pro-Hyp (3), Leu-Pro (4), Gly-Hyp (5), Gly-Pro-Ala (6), Pro-Ala (7), Pro-Gly (8), Pro-Ile (9) and Pro-Gly-Gly (10) in $25 \mathrm{mmol} / 1$ phosphate buffer at $\mathrm{pH} 10.5$; on the contrary to patterns shown in Figs. 1-7 peptides were dissolved in $17.5 \mathrm{mmol} / \mathrm{l}$ aqueous Brij solution. (B) Separation of the same set of peptides as in A except that the $\mathrm{pH}$ of the background electrolyte $(25 \mathrm{mmol} / 1$ phosphate was adjusted to 11.5). (C) Separation of the same set of peptides as in A except that the sample was dissolved in $33 \mathrm{mmol} / 1$ SDS (buffer $\mathrm{pH}$ 10.5, $25 \mathrm{mmol} / 1$ phosphate.

values; no separation is observed at the intermediate $\mathrm{pH}$ values. Optimum separation can be obtained either at $\mathrm{pH} 2.5$ or $\mathrm{pH} 8.0$ in $25 \mathrm{mmol} / 1$ phosphate buffer at $15 \mathrm{kV}$. Addition of either $10 \%$ acetonitrile or $20 \%$ methanol to the $\mathrm{pH} 8.0$ buffer resulted in a complete separation of the three members of the test set. While addition of bases (hexylamine or triethylamine) resulted only in a partial improvement (decreased sticking of the Gly-Gly dipeptide at alkaline $\mathrm{pH}$ ), making the background electrolyte 5 mmol/1 with respect to cetyltrimethyl ammonium bromide offered another possibility of how to separate the tested peptide mixture (reversed polarity mode).

For more complex peptide mixtures, however, the above rather traditional approaches are not applicable. The best results were obtained at alkaline $\mathrm{pH}$ $(10.5,25 \mathrm{mmol} / 1$ phosphate buffer) if the sample is dissolved in the presence of a detergent $(17.5 \mathrm{mmol} /$ 1 Brij 35 or $33 \mathrm{mmol} / 1 \mathrm{SDS}$ ). If either detergent is present in the background electrolyte, depending on surfactant concentration, the analytes emerge in a single peak (high concentrations) or are separated in more (two) broad sections (plateaus). The separation of the 10-component test mixture was never complete, however the selectivity can be adjusted by manipulating the $\mathrm{pH}$ of the background electrolyte or by changing the surfactant used. Generally better results were obtained with Brij 35 as compared to SDS. The main profit of these experiments is visualized in the fact that by dissolving proline and glycine rich proteins, typically $\alpha$-chains of collagen and their polymers, separation not only of the $\alpha_{1}$ and $\alpha_{2}$ chains but also of their dimers, trimers and higher polymers is possible.

The separation mechanism apparently involves interaction of the solutes with the surfactant thereby decreasing their sticking to the capillary wall.

\section{Conclusions}

(1) All attempts to optimize the separation of proline, glycine and hydroxyproline containing diand tripeptides by adjusting $\mathrm{pH}$ (i), background electrolyte concentration (ii), by exploiting methanol or acetonitrile as organic modifiers (iii) and by using hexylamine or (iv) triethylamine were only partly 


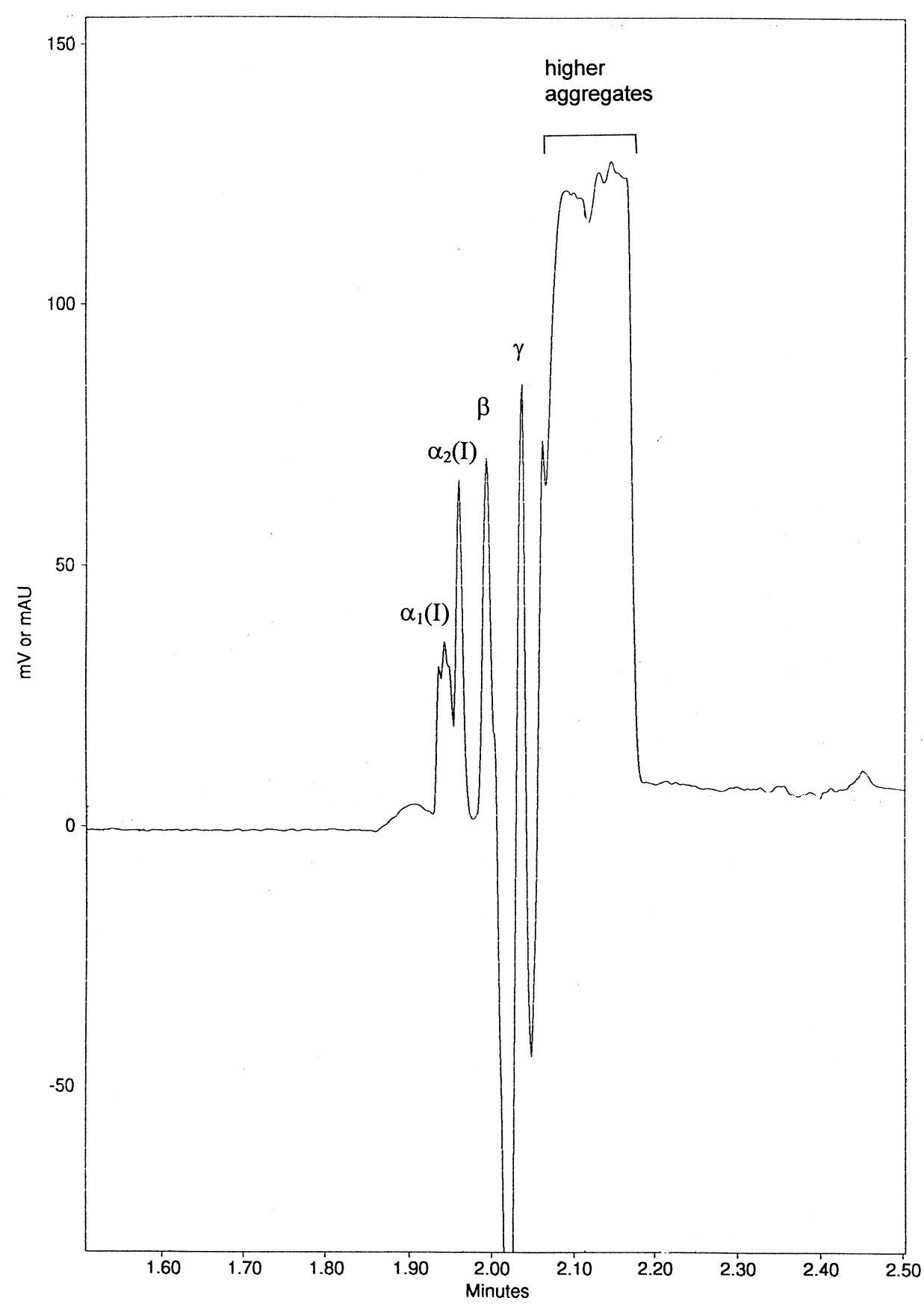

Fig. 9. Separation of collagen type I. Constituting $\alpha$-chains, $\alpha_{1}(\mathrm{I})$ and $\alpha_{2}(\mathrm{I})$, their dimers $(\beta)$ and trimers $(\gamma)$ along with high molecular mass aggregates. These aggregates disappear if the sample is boiled for a short amount of time (10 min) before application and if the sample is run at $50^{\circ} \mathrm{C}$. A corresponding increase of $\alpha$-, $\beta$ - and $\gamma$-chains was observed. Sample applied in $33 \mathrm{mmol} / 1$ Brij, background electrolyte 25 mmol/1 sodium phosphate at $\mathrm{pH} 10.5$. 
successful (distorted peaks formation) even with very simple (three component) mixtures.

(2) More complex mixtures of this category of peptides can be separated in $25 \mathrm{mmol} / \mathrm{l}$ sodium phosphate $\mathrm{pH} 10.5$ provided that samples are dissolved in $17.5 \mathrm{mmol} / 1 \mathrm{Brij}$ or $33 \mathrm{mmol} / 1 \mathrm{SDS}$.

(3) Large peptide chains containing high proportion of proline, hydroxyproline and glycine, typically collagen $\alpha$-chains, their dimers, trimers and higher aggregates can be separated in $25 \mathrm{mmol} / 1$ sodium borate at $\mathrm{pH} 10.5$ provided that the samples are dissolved in $33 \mathrm{mmol} / 1$ Brij.

(4) It is proposed that the separations are based on competitive processes involving a proportion of the analytes adsorbed to the inner wall of bare silica capillary and their association with the detergent contained in the sample (Brij micelles are not subjected to electrokinetic movement, SDS micelles migrate slowly towards anode). The presence of the detergent not only helps to materialize the partition mechanism but also helps to sweep the capillary clean from adsorbed peptide/proteins.

\section{Acknowledgements}

This work was supported by Grant Agency of the Czech Republic (Grants Nos. 203/96/K128 and 203/99/0191).

\section{References}

[1] S.F.Y. Li, Capillary Electrophoresis, Elsevier, Amsterdam, 1993.
[2] R. McCormick, Anal. Chem. 60 (1988) 2322.

[3] J. Téhrani, R. Macomber, L. Day, J. High Resolut. Chromatogr. 14 (1991) 10.

[4] K.J. Lee, G.S. Leo, J. Chromatogr. 559 (1991) 317.

[5] J.K. Towns, F. Regnier, J. Chromatogr. 516 (1990) 69.

[6] J.K. Towns, F. Regnier, Anal. Chem. 63 (1991) 1126.

[7] S.A. Swedberg, Anal. Biochem. 185 (1990) 51.

[8] Y.-F. Maa, K.J. Hyver, S.A. Svedberg, J. High Resolut. Chromatogr. 14 (1991) 65.

[9] A.M. Dougherty, C.L. Wolley, D.L. William, D.F. Swaile, R.O. Cole, M.J. Sepaniak, J. Liq. Chromatogr. 14 (1991) 907.

[10] K.A. Cobb, V. Dolnik, M. Novotny, Anal. Chem. 62 (1990) 2478.

[11] D. Bentrop, J. Kohr, H. Engelhardt, Chromatographia 32 (1991) 177.

[12] J.A. Bullock, L.C. Yuan, J. Microcol. Separ. 3 (1991) 241.

[13] D. Corradini, G. Cannarsa, LC·GC Int. 9 (1996) 34.

[14] J. Green, J. Jorgenson, J. Chromatogr. 478 (1989) 63.

[15] M. Bushey, J. Jorgenson, J. Chromatogr. 480 (1989) 301.

[16] J. Novotná, Z. Deyl, I. Mikšík, J. Chromatogr. B 681 (1996) 77.

[17] I. Mikšík, J. Novotná, M. Uhrová, D. Jelínková, Z. Deyl, J. Chromatogr. A 772 (1997) 213.

[18] S. Ayad, R. Boot-Handford, M.J. Humphries, K.E. Kadler, A. Shuttleworth, The Extracellular Matrix FactBook, Academic Press, London, 1994.

[19] J.F. Banks, in: Advanced Chromatographic and Electromigration Methods in BioSciences (Journal of Chromatography Library, Vol. 60), Z. Deyl, I. Mikšík, F. Tagliaro and E. Tesarová (Eds.), Elsevier, Amsterdam, 1998, Ch. 13, p. 525.

[20] D.K. Lloyd, H. Wätzig, J. Chromatogr. B 663 (1995) 400. 